\title{
Research Paper \\ Biological Mechanism of Extracorporeal Shock Wave Combined with Platelet-Rich Plasma on the Healing of Reconstructed Tendon Bone in a Rabbit Model of Rotator Cuff \\ Tear
}

L. HAN, H. J. FU, P. LI' ${ }^{1}$ Y. G. HU AND JING JING LIU2*

Department of Orthopaedics, ${ }^{1}$ Department of Anesthesiology, Xiaoshan Traditional Chinese Medical Hospital, Hangzhou, Zhejiang 311201, ' 2 Department of Rheumatology and Immunology, The Third Affiliated Hospital of Zhejiang Chinese Medical University, Hangzhou, Zhejiang 310005, China

Han et al.: Extracorporeal Shock Wave Combined with Platelet-Rich Plasma on Reconstructed Tendon Bone

To investigate the biological mechanism of the effect of extracorporeal shock wave combined with plateletrich plasma on the healing of reconstructed tendon bone in a rabbit model of rotator cuff tear. 40 New Zealand white rabbits aged 4-5 mo were selected, 32 rabbits were randomly selected and each rabbit was executed at 4-8 w postoperatively and these rabbits were randomly divided into control group, shockwave group, platelet-rich plasma group and shockwave+platelet-rich plasma group. The tendon bone healing site was observed at 2, 4 and $8 \mathrm{w}$ after surgery and the content of transforming growth factor beta 1 and basic fibroblast growth factor were measured by reverse transcription-polymerase chain reaction and western blot, while the biomechanical test was performed on the tendon bone healing specimens. The results showed that the content of neovascularization at the tendon-bone interface at $4 \mathrm{w}$ and $8 \mathrm{w}$ was significantly increased in shockwave, platelet-rich plasma and shockwave+platelet-rich plasma groups. The basic fibroblast growth factor and transforming growth factor beta 1 messenger RNA and protein expression tended to increase after surgery in all four groups and the levels in shockwave, plateletrich plasma and shockwave+platelet-rich plasma groups was significantly increased, while the highest expression in shockwave+platelet-rich plasma group. The maximum load force of the 3 experiment groups was all significantly increased. Besides, the maximum tensile distance was significantly longer in shockwave+platelet-rich plasma group. The combination of extracorporeal shockwave and plateletrich plasma showed optimal performance in the tensile performance of the supraspinatus tendon-bone combination, the maturity of the tendon-bone interface and the content of growth factors that promote the healing of the tendon bone, indicating that the combination of extracorporeal shock wave and plateletrich plasma can promote the healing process of the tendon bone after rotator cuff tears and improve its strength and ultimate load.

Key words: Extracorporeal shock wave, platelet-rich plasma, rotator cuff tears

Rotator cuff injury is the most common cause of shoulder dysfunction and pain in life and exercise. The incidence rate is $20.7 \%$ in the crowd, while the incidence rate is increased to $50 \%$ in the population aged $80 \mathrm{y}$ or above ${ }^{[1]}$. Complete rotator cuff tears usually require surgical repair, while partial rotator cuff tears are usually treated by non-surgical treatment, such as local use of hormones, local anesthetics and nonsteroidal anti-inflammatory drugs. However, due to the lack of blood supply and limited regeneration capacity of tendon itself, the effect of conservative treatment is usually not satisfactory. During a 10 y follow-up, 90 $\%$ of patients treated with arthroscopic surgery were satisfied, but only 50\%-60\% of patients were treated with non-surgical treatment. Most of the studies on the treatment of partial rotator cuff injury are surgical techniques. However, few studies focus on conservative treatment and new treatment of partial rotator cuff injury, such as the use of Platelet-Rich Plasma (PRP).

*Address for correspondence

E-mail: Iwl6505@tom.com 
Extracorporeal Shock Wave (ESW) is a kind of pulse wave, which propagates in the way of sound energy. It can penetrate the shallow tissue of human body with low acoustic impedance and reach deep tissue directly. When encountering bone, tendon and other media with high acoustic impedance, it can enhance the expression of various active factors through multiple effects such as force chemical signal transduction ${ }^{[2-4]}$. Besides, ESW induces capillary proliferation, collagen deposition, cell proliferation and differentiation through biochemical action and promotes bone formation, tendon repair and tissue molding ${ }^{[5,6]}$. Thus, the positive effect of ESV in the clinical application of orthopedic diseases has been recognized and valued by more and more clinicians ${ }^{[7-9]}$. At present, in terms of rotator cuff injury healing, although there is a certain consensus on the application of ESW in promoting the healing of rotator cuff injury, there is still no clear consensus on the exact mechanism of accelerating the healing process and the specific application method of ESW ${ }^{[10-12]}$. In present study, we tried to investigate the biological mechanism of the effect of ESW combined with PRP on the healing of reconstructed tendon bone in a rabbit model of rotator cuff tear.

\section{MATERIALS AND METHODS}

\section{Animals:}

40 male or female healthy New Zealand white rabbits (aged 4-5 mo, weighed about 1.8-3.1 kg, with an average of $2.5 \mathrm{~kg}$ ) were selected and raised in the environment of $22-24^{\circ}$ and humidity of $50 \%-60 \%$. The animals could eat and drink freely.

\section{Main equipment and materials:}

The $10 \%$ formaldehyde solution, $10 \%$ Ethylenediamine Tetraacetic Acid (EDTA) phosphate buffer solution, xylene, methyl methacrylate, butyl methacrylate and methyl benzoate used in this experiment were purchased from Tianjin BASF Chemical Co., Ltd. Polymerase Chain Reaction (PCR) kits and the design of primer were provided by Shanghai Bioengineering Company.

\section{Methods:}

After 40 New Zealand white rabbits adapted to the environment, 32 rabbits were randomly taken out for the surgery and divided into four groups: Control grouponly underwent the cuff tear and the routine disinfection treatment was carried out and no other treatment was given; PRP group-underwent the cuff tear and treated with $0.2 \mathrm{ml}$ PRP; Shockwave group-underwent the cuff tear and intervened with ESW (frequency $4 \mathrm{~Hz}$, pressure 1 bar), energy output was $0.16 \mathrm{~mJ} / \mathrm{mm}^{2}, 1500$ shock/time, once a time for every $3 \mathrm{~d}$, a total of 5 times; $\mathrm{PRP}+$ Shockwave group-underwent the cuff tear and treated with $0.2 \mathrm{ml}$ PRP combined with ESW. The remaining 8 rabbits were prepared for death and loss due to anesthesia, surgical trauma and postoperative infection during the experiment.

\section{Construction of the rabbit model of rotator cuff tears:}

In this study, the rotator cuff tear model was established according to Kim et al..$^{[13]}$ and the left side was selected for operation. The main steps were as follows: Shave the hair around the left shoulder, disinfect the surgical area and make an incision in the skin and fascia to expose the deltoid muscle. The deltoid muscle was cut at the distal end and the supraspinatus muscle was separated from other muscles with sharp curved forceps and the supraspinatus tendon attached to the humerus was cut off. Then, the truncated ends of deltoids were sutured to each other. After confirming that the operation was completed and the examination effect was satisfactory, the subcutaneous and incision skin were sutured successively with No. 0 silk thread, the wound was wiped with iodophor cotton ball, covered with iodophor gauze and fixed with aseptic auxiliary materials and the wound was not treated by braking. The animals were given gentamicin sulfate injection 80 000 units, intramuscular injection for three consecutive days, once a day and the wound dressing was changed according to the situation to avoid wound infection.

\section{Specimen collection:}

At $4 \mathrm{w}$ and $8 \mathrm{w}$ after operation, the supraspinatus BoneTendon Junction (BTJ) of the four groups were cut and kept as specimens. In brief, after anesthetized, the specimens were cut at $1.5 \mathrm{~cm}$ above and $1.0 \mathrm{~cm}$ below the supraspinatus BTJ. 16 specimens were randomly selected and fixed with $10 \%$ formaldehyde solution to make tissue sections. Hematoxylin and Eosin (HE) staining was performed to observe the tissues. The remaining 16 specimens were stored in liquid nitrogen for Quantitative Reverse Transcription Polymerase Chain Reaction (qRT-PCR) to calculate the messenger Ribonucleic acid (mRNA) and protein expressions of Transforming Growth Factor Beta 1 (TGF- $\beta 1$ ) and basic Fibroblast Growth Factor (bFGF).

\section{HE staining:}

The slices were put into ethylene glycol ether acetate for $1 \mathrm{~h}$, then dehydrated with anhydrous ethanol, 95 $\%$ ethanol, $90 \%$ ethanol and $80 \%$ ethanol for $5 \mathrm{~min}$, 
respectively and then washed with distilled water for $20 \mathrm{~s}$. Then the slices were stained with hematoxylin for $1 \mathrm{~min}$ and then blued in warm water for $10 \mathrm{~min}$, differentiated by $1 \%$ hydrochloric acid ethanol for $5 \mathrm{~s}$, washed with running water for $15 \mathrm{~min}$ and then blued in warm water for $2 \mathrm{~min}$. Then the slices were stained with $0.5 \%$ eosin ethanol for $2 \mathrm{~min}$ and washed with distilled water for $20 \mathrm{~s}$. After then, the slices were differentiated with $50 \%$ ethanol and dehydrated with anhydrous ethanol, $95 \%$ ethanol, $90 \%$ ethanol and 80 $\%$ ethanol for $1 \mathrm{~min}$, respectively. Finally, the slices were transparent treated with xylene twice, about 2 min each time and sealed with neutral gum.

\section{qRT-PCR:}

According to the manufacturer's instruction, total RNA was isolated from tissue samples using Trizol reagent. Complementary Deoxyribonucleic Acid (cDNA) was synthesized from total RNA using the first strand cDNA synthesis kit. RT-PCR was performed with SYBR Green qPCR master mix kit. The process of qRT-PCR was as follows: The primer sequences (Table 1) were cycled 40 times at $95^{\circ}$ for $10 \mathrm{~s}, 60^{\circ}$ for $30 \mathrm{~s}$ and $72^{\circ}$ for $15 \mathrm{~s}$. Glyceraldehyde 3-Phosphate Dehydrogenase (GAPDH) was used as the internal control. The relative expression of mRNA was calculated by $2^{-\Delta \Delta C T}$.

\section{Western blot:}

The total protein extracted using lysate buffer was determined by radioimmunoassay and separated by Sodium Dodecyl Sulphate-Polyacrylamide Gel Electrophoresis (SDS-PAGE) (Bio-Rad, USA). The protein was transferred to Polyvinylidene Fluoride (PVDF) membrane and sealed with $5 \%$ skim milk for 1 $\mathrm{h}$. The membrane was incubated with the first antibody against TGF- $\beta 1$ and bFGF at $4^{\circ}$ overnight. Next, after incubation with the second antibody, the immune complex was revealed by enhanced chemiluminescence. The relative protein expression was determined by optical densitometry using ImageJ software.

\section{Biomechanical measurement:}

At $4 \mathrm{w}$ and $8 \mathrm{w}$ after operation, 12 specimens were taken from each group and put into normal saline to prevent the tissue from drying and shrinking, which would affect the results. The distal calcaneal and supraspinatus tendons were fixed on the biomechanical tester respectively. The maximum load force of supraspinatus tendon and calcaneus separation and the maximum tensile distance of supraspinatus tendon at the maximum load force were recorded.

\section{Statistical analysis:}

The quantitative analysis of gene expression was repeated 3 times in each group. All data were expressed by $\mathrm{x} \pm \mathrm{s}$ and analyzed by Statistical Package for the Social Sciences (SPSS) 22.0 software. The comparison between two samples was performed by t test, $p<0.05$ meant the difference was significant.

\section{RESULTS AND DISCUSSION}

Neovascularization in four groups was compared. The results showed that there was no significant change in the content of the neovascularization at the tendon bone interface after $2 \mathrm{w}$ operation $(\mathrm{p}>0.05)$. Compared with control group, the content of neovascularization at tendon bone interface in shockwave, PRP and shockwave+PRP groups were all increased significantly at $4 \mathrm{w}$ and $8 \mathrm{w}(* \mathrm{p}<0.05, * * \mathrm{p}<0.01, * * * \mathrm{p}<0.001)$, as shown in fig. 1.

Protein expressions of $\mathrm{bFGF}$ and mRNA in four groups were compared. From $4 \mathrm{w}$ to $8 \mathrm{w}$ after operation, the mRNA and protein expressions of bFGF tended to increase in all four groups. However, the mRNA and protein expressions of bFGF in PRP group and shockwave+PRP group were higher than those in the control group at $4 \mathrm{w}$ and $8 \mathrm{w}$ after operation and those in the combination group was the highest $\left({ }^{*} \mathrm{p}<0.05\right.$, $* * \mathrm{p}<0.01, * * * \mathrm{p}<0.001)$, as shown in fig. 2 .

TABLE 1: PRIMER SEQUENCES

\begin{tabular}{llc}
\hline Gene & & Sequences \\
\hline TGF-B1 & Forward & 5'-ACAGCAGCAGCCTAGCAACTC-3' \\
& Reverse & 5'-CGGTTCGAGAAGTTTTTGAAGAG-3' \\
bFGF & Forward & 5'-CAACACATCAGAGCTCCGAGAA-3' \\
& Reverse & 5'-AAGGCGAAAGCCCTCAATTT-3' \\
GRPDH & Forward & 5'-GAACGGGAAGCTCACTGGC-3' \\
& Reverse & 5'-GCATGTCAGATCCACAACGG-3' \\
\hline
\end{tabular}



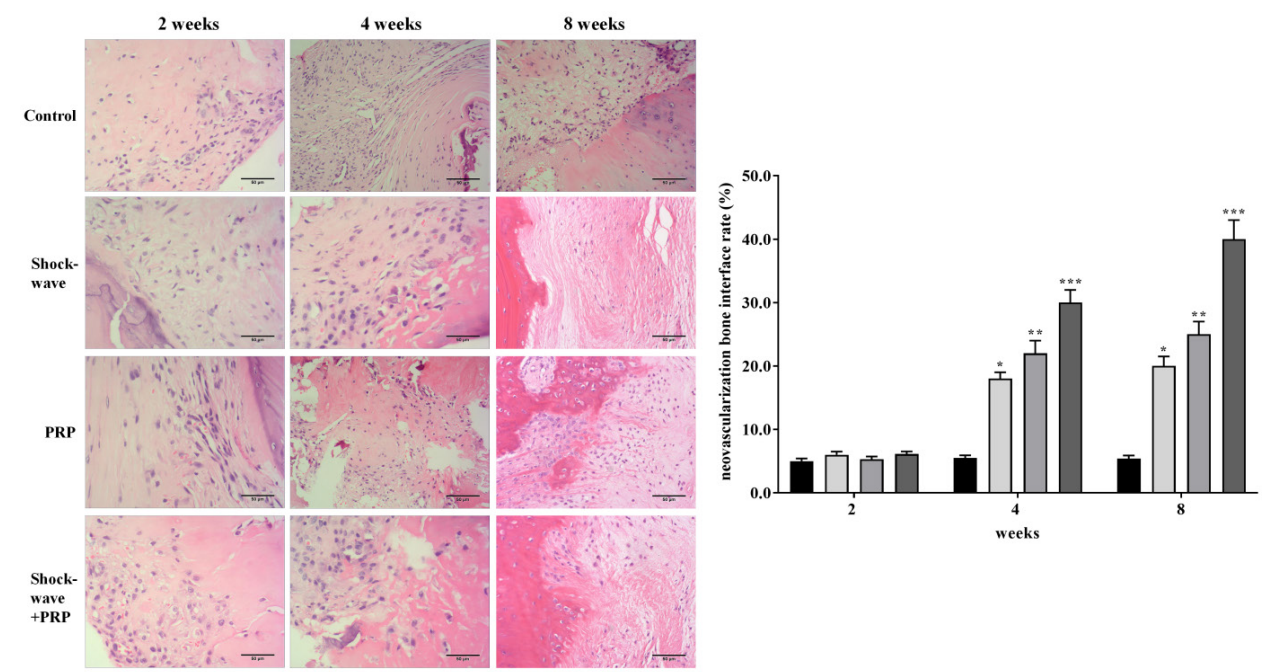

Fig. 1: Comparison of neovascularization among four groups; ${ }^{*} \mathbf{p}<0.05, * * p<0.01, * * * p<0.001, v s$. control group, (口) Control; (口)Shockwave; (口) PRP; (口) Shockwave+PRP
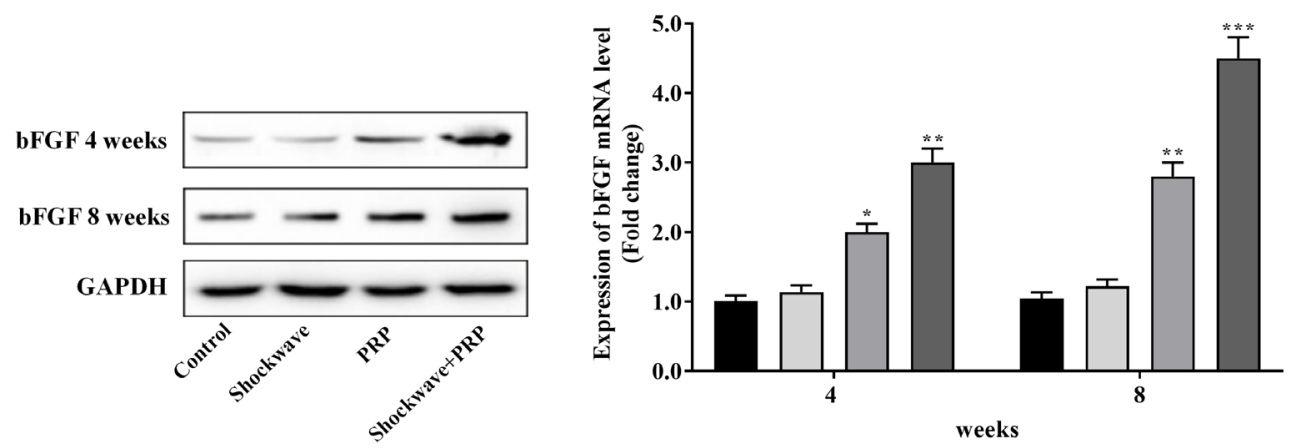

Fig. 2: Comparison of mRNA and protein expressions of bFGF in four groups; ${ }^{*} \mathbf{p}<0.05, * * \mathbf{p}<0.01, * * * p<0.001$, vs. control group,

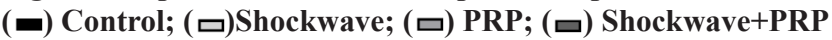

Protein expressions of TGF- $\beta 1$ and mRNA in four groups were compared. From $4 \mathrm{w}$ to $8 \mathrm{w}$ after operation, the mRNA and protein expressions of TGF- $\beta 1$ tended to increase in all four groups. However, the mRNA and protein expressions of TGF- $\beta 1$ in PRP and shockwave+PRP group were higher than those in control group at $4 \mathrm{w}$ and $8 \mathrm{w}$ after operation and those in the combination group was the highest $\left({ }^{*} p<0.05\right.$, $* * \mathrm{p}<0.01, * * * \mathrm{p}<0.001)$, as shown in fig. 3 .
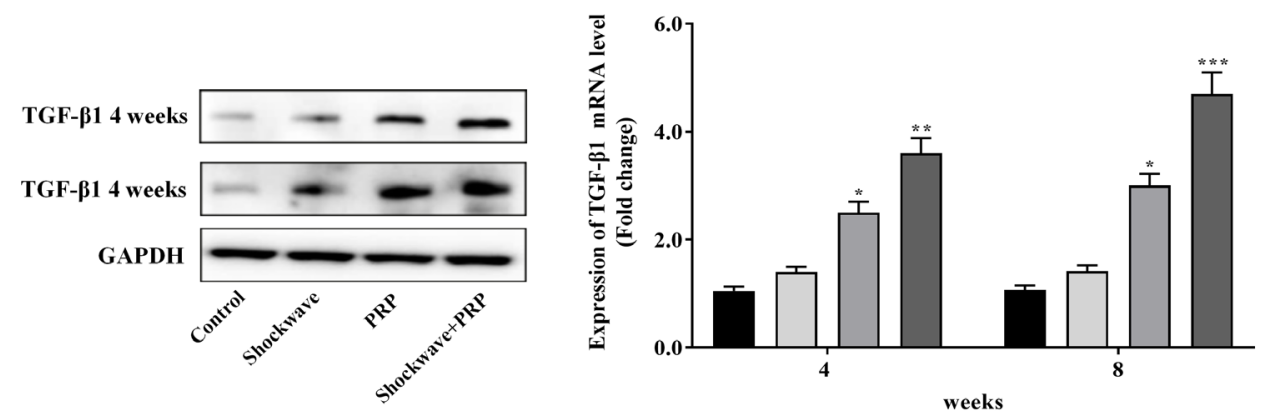

Fig. 3: Comparison of mRNA and protein expressions of TGF- $\beta 1$ in four groups; ${ }^{*} \mathbf{p}<0.05, * * p<0.01, * * * p<0.001$, vs. control group

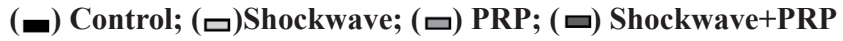


Biomechanical indexes in four groups were compared. The maximum load force of supraspinatus tendon and calcaneus separation in control group was (31.55 \pm 4.20$)$ $\mathrm{N}$ and $(63.25 \pm 3.70) \mathrm{N}$ at $4 \mathrm{w}$ and $8 \mathrm{w}$ after operation, respectively. The maximum load force of supraspinatus tendon and calcaneus separation in PRP group was $(65.75 \pm 7.80) \mathrm{N}$ and $(95.20 \pm 6.90) \mathrm{N}$ at $4 \mathrm{w}$ and $8 \mathrm{w}$ after operation, respectively. The maximum load force of supraspinatus tendon and calcaneus separation in shockwave group was $(64.15 \pm 8.20) \mathrm{N}$ and $(96.15 \pm 6.70) \mathrm{N}$ at $4 \mathrm{w}$ and $8 \mathrm{w}$ after operation, respectively. The maximum load force of supraspinatus tendon and calcaneus separation in shockwave+PRP group was $(78.37 \pm 10.45) \mathrm{N}$ and $(108.90 \pm 9.10) \mathrm{N}$ at $4 \mathrm{w}$ and $8 \mathrm{w}$ after operation, respectively (fig. 4A). The maximum tensile distance of supraspinatus tendon and calcaneus separation in control group was $(1.59 \pm 0.10) \mathrm{cm}$ and $(1.81 \pm 0.08) \mathrm{cm}$ at $4 \mathrm{w}$ and $8 \mathrm{w}$ after operation, respectively. The maximum tensile distance of supraspinatus tendon and calcaneus separation in PRP group was $(2.05 \pm 0.03) \mathrm{cm}$ and $(2.14 \pm 0.05)$ $\mathrm{cm}$ at $4 \mathrm{w}$ and $8 \mathrm{w}$ after operation, respectively. The maximum tensile distance of supraspinatus tendon and calcaneus separation in shockwave group was $(1.91 \pm 0.06) \mathrm{cm}$ and $(2.10 \pm 0.07) \mathrm{cm}$ at $4 \mathrm{w}$ and $8 \mathrm{w}$ after operation, respectively. The maximum tensile distance of supraspinatus tendon and calcaneus separation in shockwave+PRP group was $(2.87 \pm 0.04)$ $\mathrm{cm}$ and $(3.45 \pm 0.15) \mathrm{cm}$ at $4 \mathrm{w}$ and $8 \mathrm{w}$ after operation, respectively (fig. 4B). The maximum load force of the 3 experiment groups were all significantly higher than that of control group no matter at $4 \mathrm{w}$ or $8 \mathrm{w}$ after operation $(* p<0.05, * * p<0.01)$. Besides, the maximum tensile distance were significant longer in shockwave+PRP group than that of control group no matter at $4 \mathrm{w}$ or 8 $\mathrm{w}$ after operation $(* * \mathrm{p}<0.01)$, but showed no significant difference in shockwave and PRP group compared with control group ( $\mathrm{p}>0.05)$.

A

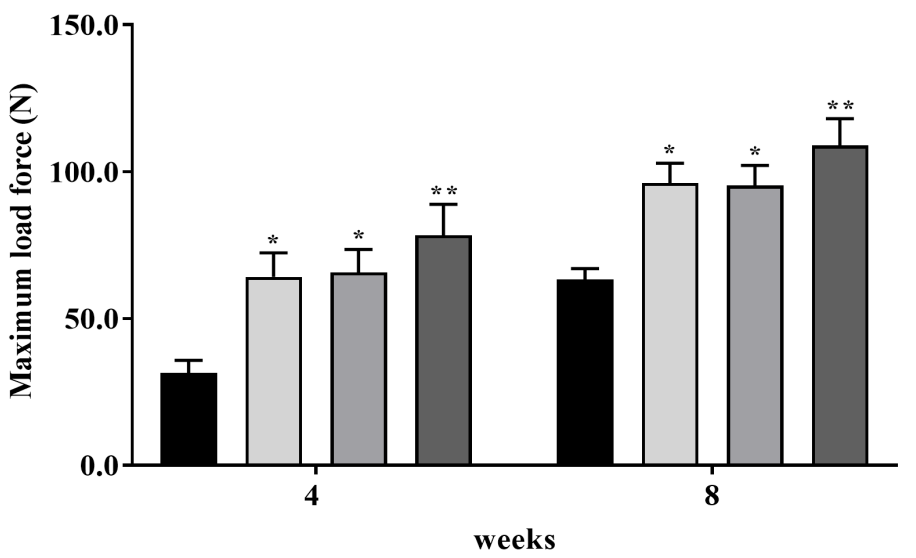

B

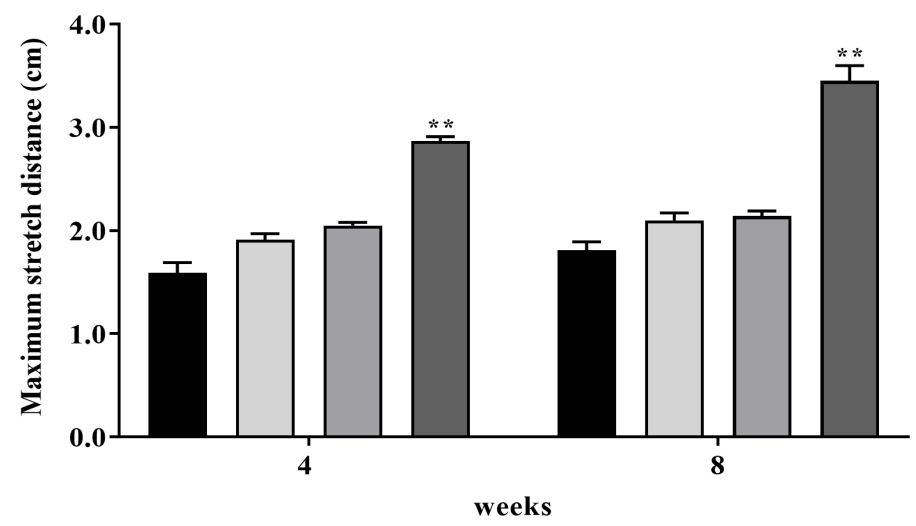

Fig. 4: Comparison of the maximum load force and the maximum tensile distance in four groups, (A) The maximum load force; (B)

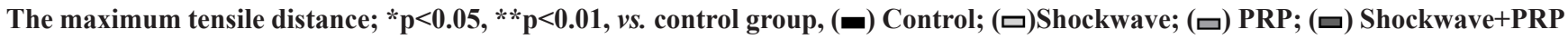


PRP was invented in 1970s and its first use was in a heart bypass operation in Italy in 1987. As a product of autologous blood, PRP can be used in various fields of medicine due to its advantages of less trauma, simple preparation and potential biological therapeutic effects $^{[14-16]}$. The rich growth factors in PRP were all located in circulating platelet granules. The platelets release a large number of bioactive growth factors through degranulation to promote tissue repair. Among them, platelet-derived growth factor is the most critical growth factor in the early stage of tissue healing ${ }^{[17]}$, which can promote the chemotaxis and mitosis of related tissue cells, especially stem cells, fibroblasts and chondrocytes $^{[18]}$, but also chemotactic inflammatory cells to produce cascade growth factor release ${ }^{[19]}$; TGF can promote cell proliferation and differentiation, as well as matrix synthesis; Vascular Endothelial Growth Factor (VEGF) can promote the migration and mitosis of endothelial cells and stimulate angiogenesis after binding with endothelial cell surface receptors; Endothelial growth factor can cooperate with VEGF to promote angiogenesis.

ESW is a kind of pulse wave, which propagates in the way of sound energy. It can penetrate the shallow tissue of human body with low acoustic impedance and reach deep tissue directly. When encountering bone, tendon and other media with high acoustic impedance, it can enhance the expression of various active factors through multiple effects such as force chemical signal transduction ${ }^{[9]}$. Besides, ESW induces capillary proliferation, collagen deposition, cell proliferation and differentiation through biochemical action and promotes bone formation, tendon repair and tissue molding. Previous studies showed that the application of ESW to the BTJ after tendon and ligament injury reconstruction can significantly improve the healing speed of BTJ and improve its stiffness, toughness and maximum load resistance. ESW mainly produces specific effects through cavitation effect, stress effect, piezoelectric effect and stress-chemical signal transduction effect. It plays a positive role in stem cell aggregation and expression of various active factors, which helps to promote angiogenesis, tendon repair and induce bone growth and molding, so as to promote tissue healing ${ }^{[10,20,21]}$.

In view of the important role of bFGF and TGF- $\beta 1$ in the whole process of tendon bone healing, qRT-PCR was used to detect the expression of bFGF and TGF- $\beta 1$ at gene level. These results showed that from $4 \mathrm{w}$ to 8 $\mathrm{w}$ after operation, the mRNA and protein expressions of bFGF and TGF- $\beta 1$ tended to increase in all four groups, though no statistical significance was found, respectively $(\mathrm{p}>0.05)$. However, the mRNA and protein expressions of bFGF and TGF- $\beta 1$ in the PRP group, the shockwave group and the combination group were higher than those in the control group at $4 \mathrm{w}$ and $8 \mathrm{w}$ after operation $(p<0.05)$. It should be noted that the expressions of bFGF and TGF- $\beta 1$ in the combination group were the highest at $4 \mathrm{w}$ and $8 \mathrm{w}$ after operation and there was significant difference compared with other groups $(\mathrm{p}<0.05)$. Therefore, the results indicated that ESW and PRP can promote the regulation of vascular number and collagen deposition, positively regulate the proliferation, growth and differentiation of osteoblasts, accelerate tissue shaping and shorten the time of fibrocartilage band formation by regulating the expression of bFGF and TGF- $\beta 1$. And these two methods have a synergistic effect.

In this experiment, the rabbit rotator cuff tear model was established by cutting the supraspinatus tendon to imitate the rupture of human supraspinatus tendon. After reconstruction, low-energy ESW intervention and PRP injection were applied around the supraspinatus tendon for several times and the control group was set up without intervention to observe and analyze the effect of ESW on tendon bone healing and remodeling of supraspinatus BTJ in rabbits. In this experiment, compared with the control group, the maximum load force of shockwave group, PRP group and combination group were significantly increased and that of combined group was the largest, but there was no significant difference between the shockwave group and PRP group. In addition, compared with the control group, the maximum tensile distance of shockwave group, PRP group and combination group were significantly increased, and that of combined group was the largest, but there was no significant difference between the shockwave group and PRP group $(\mathrm{p}<0.05)$. Besides, there were significant differences in the maximum load force and the maximum tensile distance in different time periods in each group, respectively $(p<0.05)$. These results of biomechanical test demonstrated that both ESW and PRP can improve the toughness, stiffness and maximum tensile load of the reconstructed supraspinatus tendon and increase its biomechanical properties.

In conclusion, the combination of ESW and PRP showed optimal performance in the tensile performance of the supraspinatus tendon-bone combination, the maturity of the tendon-bone interface and the content of growth 
factors that promote the healing of the tendon bone, indicating that the combination can promote the healing process of the tendon bone after rotator cuff tears and improve its strength and ultimate load.

\section{Acknowledgements:}

This study was supported by the Technology Department of Xiaoshan Traditional Chinese Medical Hospital, Hangzhou, China

\section{Conflict of interests:}

The authors declared no conflict of interest.

\section{REFERENCES}

1. Farnebo S, Woon CY, Bronstein JA, Schmitt T, Lindsey DP, Pham $\mathrm{H}$, et al. Decellularized tendon-bone composite grafts for extremity reconstruction: An experimental study. Plast Reconstr Surg 2014;133(1):79-89.

2. Benjamin M, Evans EJ, Copp L. The histology of tendon attachments to bone in man. J Anat 1986;149(4):89.

3. Farnebo S, Woon CY, Bronstein JA, Schmitt T, Lindsey DP, Pham $\mathrm{H}$, et al. Decellularized tendon-bone composite grafts for extremity reconstruction: An experimental study. Plast Reconstr Surg 2014;133(1):79-89.

4. Maguire M, Goldberg J, Bokor D, Bertollo N, Pelletier MH, Harper W, et al. Biomechanical evaluation of four different transosseous-equivalent/suture bridge rotator cuff repairs. Knee Surg Sports Traumatol Arthrosc 2011;19(9):1582-7.

5. Baums MH, Schminke B, Posmyk A, Miosge N, Klinger HM, Lakemeier S. Effect of single-and double-row rotator cuff repair at the tendon-to-bone interface: Preliminary results using an in vivo sheep model. Arch Orthop Trauma Surg 2015;135(1):111-8.

6. Song G, Habibovic P, Bao C, Hu J, Van Blitterswijk CA, Yuan $\mathrm{H}$, et al. The homing of bone marrow MSCs to non-osseous sites for ectopic bone formation induced by osteoinductive calcium phosphate. Biomaterials 2013;34(9):2167-76.

7. Zhang Z, Gu B, Zhu W, Zhu L, Li Q. Arthroscopic versus mini-open rotator cuff repair: A prospective, randomized study with 24-month follow-up. Eur J Orthop Surg Traumatol 2014;24(6):845-50.

8. Ciampi P, Scotti C, Nonis A, Vitali M, di Serio C, Peretti $\mathrm{GM}$, et al. The benefit of synthetic versus biological patch augmentation in the repair of posterosuperior massive rotator cuff tears: A 3-year follow-up study. Am J Sports Med 2014;42(5):1169-75.

9. de Wall M, Scholes CJ, Patel S, Coolican MR, Parker DA. Tibial fixation in anterior cruciate ligament reconstruction: A prospective randomized study comparing metal interference screw and staples with a centrally placed polyethylene screw and sheath. Am J Sports Med 2011;39(9):1858-64.

10. Wang CJ, Wang FS, Yang KD, Weng LH, Sun YC, Yang YJ. The effect of shock wave treatment at the tendon-bone interface-An histomorphological and biomechanical study in rabbits. J Orthop Res 2005;23(2):274-80.
11. Foldager CB, Kearney C, Spector M. Clinical application of extracorporeal shock wave therapy in orthopedics: Focused versus unfocused shock waves. Ultrasound Med Biol 2012;38(10):1673-80.

12. Gollwitzer H, Saxena A, diDomenico LA, Galli L, Bouché RT, Caminear DS, et al. Clinically relevant effectiveness of focused extracorporeal shock wave therapy in the treatment of chronic plantar fasciitis: A randomized, controlled multicenter study. J Bone Joint Surg Am 2015;97(9):701-8.

13. Kim SJ, Kim EK, Kim SJ, Song DH. Effects of bone marrow aspirate concentrate and platelet-rich plasma on patients with partial tear of the rotator cuff tendon. J Orthop Surg Res 2018;13(1):1-7.

14. Canapp Jr SO, Canapp DA, Ibrahim V, Carr BJ, Cox C, Barrett JG. The use of adipose-derived progenitor cells and plateletrich plasma combination for the treatment of supraspinatus tendinopathy in 55 dogs: A retrospective study. Front Vet Sci 2016;3:61.

15. Kim SJ, Lee SM, Kim JE, Kim SH, Jung Y. Effect of plateletrich plasma with self-assembled peptide on the rotator cuff tear model in rat. J Tissue Eng Regen Med 2017;11(1):77-85.

16. Shams A, El-Sayed M, Gamal O, Ewes W. Subacromial injection of autologous platelet-rich plasma versus corticosteroid for the treatment of symptomatic partial rotator cuff tears. Eur J Orthop Surg Traumatol 2016;26(8):837-42.

17. Lädermann A, Zumstein MA, Kolo FC, Grosclaude M, Koglin L, Schwitzguebel AJ. In vivo clinical and radiological effects of platelet-rich plasma on interstitial supraspinatus lesion: Case series. Orthop Traumatol Surg Res 2016;102(8):977-82.

18. von Wehren L, Blanke F, Todorov A, Heisterbach P, Sailer $\mathrm{J}$, Majewski M. The effect of subacromial injections of autologous conditioned plasma versus cortisone for the treatment of symptomatic partial rotator cuff tears. Knee Surg Sports Traumatol Arthrosc 2016;24(12):3787-92.

19. Rha DW, Park GY, Kim YK, Kim MT, Lee SC. Comparison of the therapeutic effects of ultrasound-guided platelet-rich plasma injection and dry needling in rotator cuff disease: A randomized controlled trial. Clin Rehabil 2013;27(2):113-22.

20. Kovacevic D, Fox AJ, Bedi A, Ying L, Deng XH, Warren $\mathrm{RF}$, et al. Calcium-phosphate matrix with or without TGF- $\beta 3$ improves tendon-bone healing after rotator cuff repair. Am J Sports Med 2011;39(4):811-9.

21. Apostolakos J, Durant TJ, Dwyer CR, Russell RP, Weinreb JH, Alaee F, et al. The enthesis: A review of the tendon-to-bone insertion. Muscles Ligaments Tendons J 2014;4(3):333-42.

This is an open access article distributed under the terms of the Creative Commons Attribution-NonCommercial-ShareAlike 3.0 License, which allows others to remix, tweak, and build upon the work non-commercially, as long as the author is credited and the new creations are licensed under the identical terms

This article was originally published in a special issue, "Novel Therapeutic Approaches in Biomedicine and Pharmaceutical Sciences" Indian J Pharm Sci 2021:83(6) Spl Issue "98-104" 